Article

\title{
Tracking Human-Induced Landscape Disturbance at the Nasca Lines UNESCO World Heritage Site in Peru with COSMO-SkyMed InSAR
}

\author{
Francesca Cigna* (D) and Deodato Tapete \\ Italian Space Agency (ASI), Via del Politecnico snc, 00133 Rome, Italy; deodato.tapete@asi.it \\ * Correspondence: francesca.cigna@asi.it; Tel.: +39-06-8567-650
}

Received: 11 March 2018; Accepted: 28 March 2018; Published: 8 April 2018

check for updates

\begin{abstract}
The "Lines and Geoglyphs of Nasca and Palpa" in Peru are among the most well-known UNESCO World Heritage Sites globally, and an exemplar of site where heritage assets cannot be separated from their natural and anthropogenic environment. The site is exposed to interactions with natural processes, as well as human presence. In this work, 3-m resolution synthetic aperture radar (SAR) StripMap HIMAGE HH-polarised scenes acquired by the X-band COSMO-SkyMed constellation are exploited to track two events of human-induced landscape disturbance that occurred in December 2014 and January 2018. Pre-, cross-, and post-event interferometric SAR (InSAR) pairs characterised by small temporal and normal baselines allow the detection of temporal decorrelation associated with the two events, the extent and time reference of which match with online photographic and video evidence, published literature, web news, and press releases by the Ministry of Culture in Peru. Further elements enhancing the understanding of the 2018 event come from 10-m resolution Sentinel-2B satellite data that reveal the occurrence of apparent changes of surface reflectance due to uncovering of the light grey-yellow clay underneath the darker pebble constituting the fragile surface of the Pampa de Jumana. This scientific study confirms that SAR imagery archives, such as those being built by COSMO-SkyMed for Nasca, prove valuable for the retrospective analysis and digital recording of human-induced landscape disturbance events from space. These archives therefore act as essential sources of geospatial information on the conservation history of heritage sites and assets.
\end{abstract}

Keywords: synthetic aperture radar; InSAR; coherence; temporal decorrelation; change detection; COSMO-SkyMed; archaeology; geoglyphs; Nasca lines; Peru

\section{Introduction}

The "Lines and Geoglyphs of Nasca and Palpa" (hereinafter called "Lines") are a Peruvian archaeological heritage site located in the Libertadores-Wari Region in southern Peru, nearly $400 \mathrm{~km}$ south of Lima (Figure 1), that were declared a UNESCO World Heritage Site (WHS) and, as such, inscribed on the World Heritage List in 1994. The Lines are "negative geoglyphs", i.e., drawings scratched on the land surface by exposing unpatinated and lighter-coloured ground once the dark gravels of the top soil are removed according to a design or pattern [1,2].

The Lines are probably among the most well-known WHS globally, and an exemplar of a site where heritage assets cannot be separated from their natural and anthropogenic environment. This character is explicitly stated in the definition of the WHS integrity: "The Lines and Geoglyphs of Nasca and Pampas de Jumana, with their protection area that extends over 75,358.47 Ha, are well defined and include all physical aspects that convey the Outstanding Universal Value of the property, including its surrounding landscape with which they make up an indivisible unit in a harmonious relationship that has survived virtually unaltered over the centuries" [3]. 
With regard to the heritage conservation, the Lines are exposed to continuous or frequent interactions with local weather and natural surface processes, as well as the human presence and its use of the land. Indeed, the last official State of Conservation report published by UNESCO cites, among others, the following human-related factors affecting the WHS: damage caused by illegal mining and farming activities, continued vehicle traffic through the geoglyphs, lack of systematic monitoring of the property, and planned infrastructure projects [4]. Concerns have been expressed in the past years about the impact on the conservation of the Lines due to climate change and potential for flooding caused by El Niño (e.g., [5,6]). There is also a history of events due to human action that have been reported in official reports, press releases of the Ministry of Culture of Peru, media, and published literature, for the surface damage and landscape disturbance they caused at various locations of this hugely wide WHS (e.g., [7-10]).

In this paper, a focus on a couple of these well-documented anthropogenic events is provided to demonstrate that synthetic aperture radar (SAR) images with high spatial resolution (HR), acquired regularly from X-band space-borne sensors (frequency range 8-12 GHz; wavelength range 2.5-3.75 cm), can be used to undertake digital fieldwork and create a digital record for the substantiation of site disturbance events.

It is not the first time that the Nasca Lines are studied using space-borne SAR, although most of the investigations relied on C-band SAR data (frequency range 4-8 GHz; wavelength range $3.75-7.5 \mathrm{~cm}$ ). In previous publications, for instance, the value of archive C-band data to analyse retrospectively landscape changes was proved [11] and the condition of heritage assets-either at surface or brought back to light by archaeological excavations-was assessed based on time series of calibrated radar backscatter and its normalized coefficient (sigma nought, $\sigma^{0}$ ) [12]. With similar approaches, other studies [13-15] also exploited a different selection of the same archive data from the ERS-1/2 and ENVISAT SAR missions of the European Space Agency (ESA), for change detection analysis based on interferometric SAR (InSAR) coherence.

The key lesson learnt from those studies was that the availability of multitemporal data acquired with consistent SAR imaging parameters is advantageous for logging events of interest with temporal accuracy. Furthermore, the different information that can be extracted from SAR time series-for example, phase, coherence, and radar backscatter-are all equally relevant and can be used selectively to highlight specific features or marks related to the studied events. However, a frequent drawback of historical SAR archives is temporal discontinuity, which results in a lack of temporal granularity, and in some cases, spatial resolution not sufficient to allow small features to be distinguished and clearly imaged from space.

Recent publications have demonstrated how current space X-and C-band SAR missions enable these limitations to be overcome in the Nasca region. These studies focus on the use of HR to very high resolution (VHR) data acquired by the German Aerospace Center (DLR) TerraSAR-X X-band mission [15,16], and the exploitation of the shorter repeat cycle and predefined observation scenario of the Copernicus Sentinel-1 C-band constellation in interferometric wide swath mode [15,17]. However, it is still to be explored the benefit that can be achieved with a SAR acquisition schedule that provides time series with HR and regular short revisiting time.

This paper aims therefore to examine the value of this combined spatial and temporal capability, by analysing X-band SAR StripMap data acquired over the Nasca Lines since 2011 by the COSMO-SkyMed (COnstellation of small Satellites for Mediterranean basin Observation) mission of the Italian Space Agency (ASI) (Figure 1). In particular, this study discusses how the existing and growing COSMO-SkyMed archive that is being built for Nasca can support the retrospective analysis of events of human-induced landscape disturbance. These events, by their nature, cannot be anticipated, but once happened, may be recorded in the digital history of the affected heritage asset based on the information that has been captured in a timely manner from space, prior to, during, and/or soon after the event itself. The research question that this paper aims to address is therefore whether changes 
of SAR properties caused in the landscape by the effect of a single event can be transformed into geospatial information for digital recording.

Section 2 introduces the SAR data stack used for this research experiment, the image processing methodology adopted for change detection and event analysis, and the rationale for the selection of the two events of human-induced landscape disturbance used for demonstration. The latter consist of: a recent event that occurred on 27 January 2018, when a truck drove off the Pan-American Highway (American media referred to it as "a rig [that] plowed into the ancient site" [18]); and an event of surface disturbance that occurred near the Hummingbird geoglyph on 8 December 2014 (see Figure 2 for pre-event photographs and aerial views of the event locations). In Section 3, the results of the SAR change detection analysis for the two selected events (black stars in Figure 1) are presented, and the advantages offered by the possibility to create multiple SAR pairs to identify the marks associated with the two selected events of landscape disturbance are specifically discussed. It is worth noting that it is beyond the scope of this paper to provide a forensic analysis of these events, hence the names and specific details of actors involved in the incidents are intentionally omitted in the text. Key conclusions and recommendations for future research studies and applications are finally summarised in Section 4 .

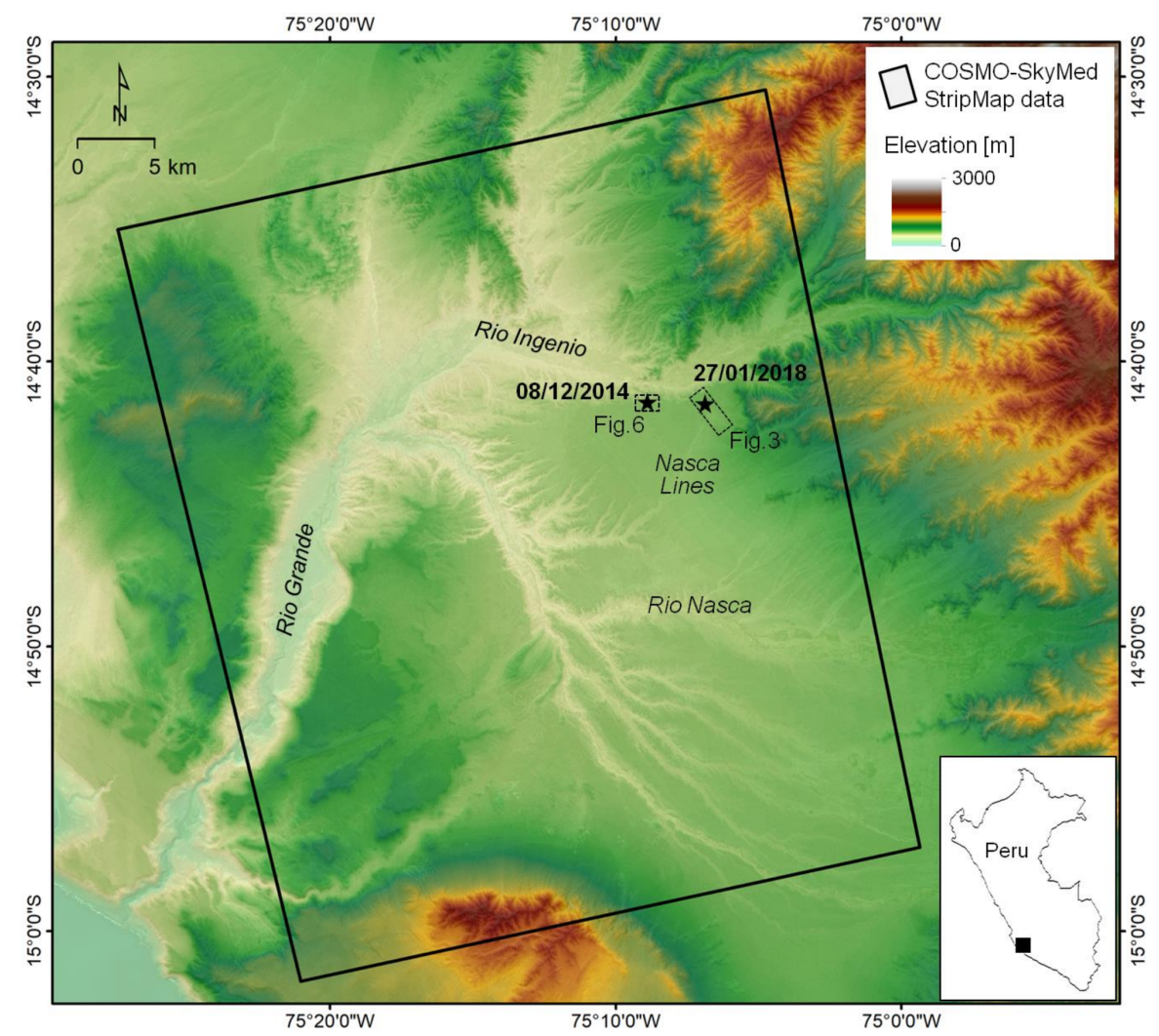

Figure 1. Location of the Nasca Lines region of interest in Peru on 30-m resolution NASA's shuttle radar topography mission (SRTM) digital elevation model, with indication of the COSMO-SkyMed StripMap image footprint (black rectangle) and areas affected by the 2014 and 2018 events (black stars). 

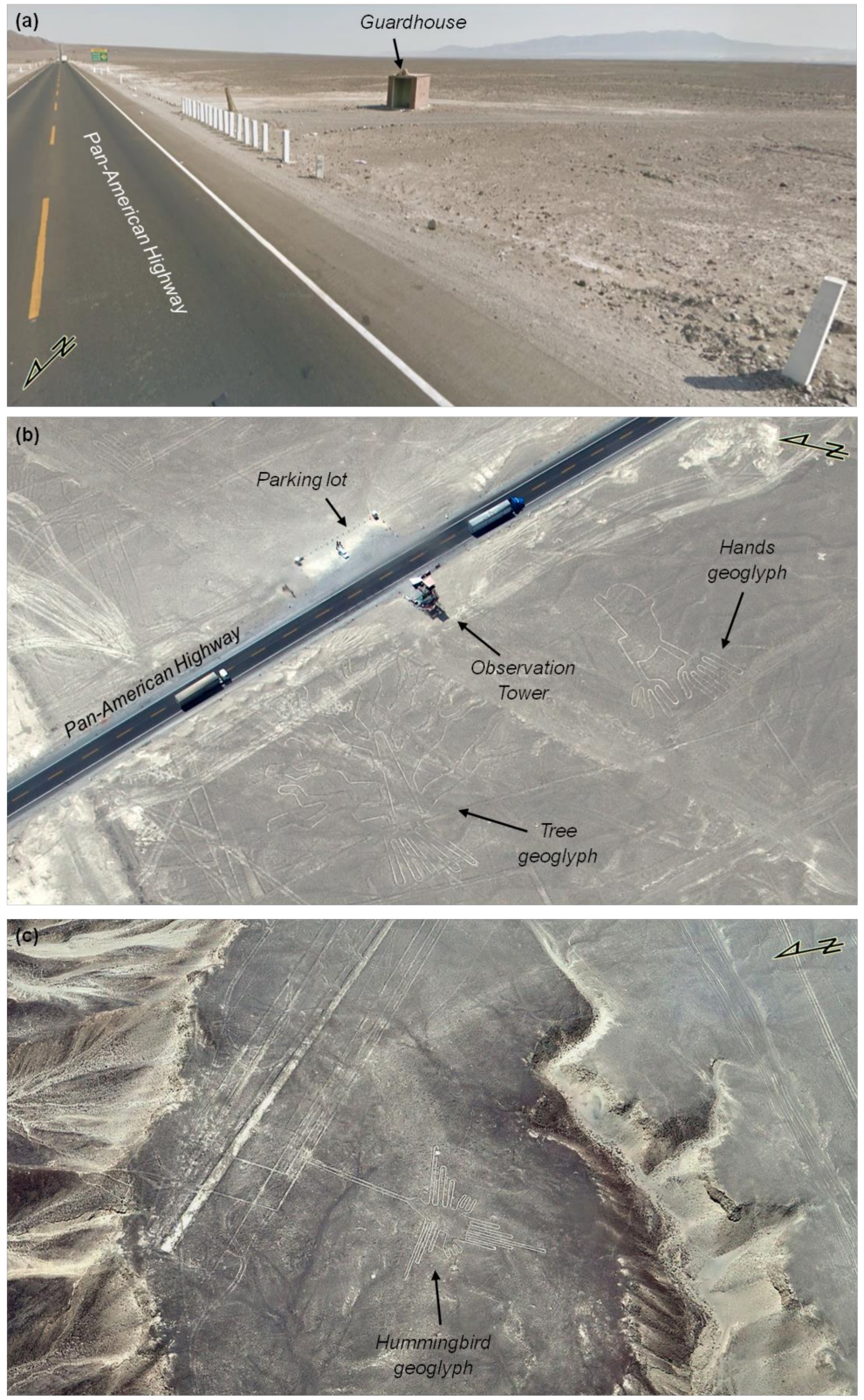

Figure 2. Overview of the locations investigated in this paper: (a) 2015 photograph of the section of the Pan-American Highway where the "plowing" event occurred on 27 January 2018 (source: Street View (C) 2018 Google); and 2013 aerial views acquired over: (b) the Observation Tower and its parking lot, with indication of the Hands and Tree geoglyphs; and (c) the plateau where the Hummingbird geoglyph is located and the surface disturbance event occurred on 8 December 2014 (photo credits: Unukorno; source: Wikimedia Commons).

\section{Materials and Methods}

For this research, images acquired by the satellite constellation COSMO-SkyMed (also referred to as CSK), a dual-use (i.e., civilian/military) programme funded by ASI and the Italian Ministry of Defence $[19,20]$, were used. The constellation is made of four identical space-crafts (i.e., CSK1, CSK2, CSK3, and CKS4), each equipped with multimode SAR sensors operating in the X-band (9.6 GHz frequency; $3.1 \mathrm{~cm}$ wavelength) and with nominal revisit time of 16 days. The CSK satellites were progressively deployed from 2007 to 2010 into a dawn-dusk sun-synchronous low Earth orbit (619.6 km nominal altitude), with the constellation becoming fully operational in the first half of 2011 [21]. 
The COSMO-SkyMed data used for this research were acquired in StripMap HIMAGE mode, hence with $40 \mathrm{~km}$ swath width, $0.9 \mathrm{~m}$ slant range, and $2.2 \mathrm{~m}$ azimuth pixel spacing (i.e., around $3 \mathrm{~m}$ ground resolution). The data stack was collected with a consistent imaging geometry, orbit mode, and beam. In particular, the ascending orbit direction with a heading angle of $12.2^{\circ}$ off the north $(\mathrm{N})$ direction and the right-looking mode was used. Acquisitions were performed with $\mathrm{HH}$ single-polarisation and using the H4-01 beam mode, with look angle ranging between $\sim 22.6^{\circ}$ and $\sim 25.6^{\circ}$ at near and far range, respectively, resulting in a $\sim 26.7^{\circ}$ incidence angle on the ground at scene centre. The images were acquired at $\sim 11.10$ am UTC (Coordinated Universal Time), i.e., $\sim 06.10 \mathrm{am}$ local time at Nasca, with scene centre at $14^{\circ} 46^{\prime} 25^{\prime \prime} \mathrm{S}, 75^{\circ} 13^{\prime} 08^{\prime \prime} \mathrm{W}$ and with an image size on the ground of 40 by $50 \mathrm{~km}$ (Figure 1).

For this analysis, two events of site disturbance occurred within the Nasca Lines WHS at two different locations (black stars in Figure 1) on 8 December 2014, and 27 January 2018, were selected. These events, described in Sections 3.1 and 3.2, were chosen for demonstration, according to the following three criteria: (i) their geographic location could be accurately identified based on published official information and pictorial evidence from published photographs and videos; (ii) the type of site disturbance caused changes that could be tracked based on the alteration of SAR properties at the surface; and (iii) they were, of course, covered by the time series of COSMO-SkyMed scenes available over Nasca.

To investigate these two events, a stack of seven scenes acquired between 10/07/2014 and 30/01/2018 was used (Table 1). Image processing started from Level 1A products, i.e., single-look complex slant range balanced (SCS_B) data. These were generated after the focusing of raw Level 0 products in slant range and zero Doppler projection, compensation of antenna transmitter gain, receiver attenuation and range spreading loss, as well as weighted processing and radiometric equalization [21].

Table 1. COSMO-SkyMed StripMap HIMAGE scenes used for the analysis of the December 2014 and January 2018 events that occurred within the Nasca Lines WHS at the locations reported in Figures 1 and 2.

\begin{tabular}{cc}
\hline Image Date (DD/MM/YYYY) & Satellite \\
\hline $10 / 07 / 2014$ & COSMO-SkyMed 2 \\
$12 / 04 / 2015$ & COSMO-SkyMed 4 \\
$13 / 12 / 2017$ & COSMO-SkyMed 4 \\
$10 / 01 / 2018$ & COSMO-SkyMed 2 \\
$18 / 01 / 2018$ & COSMO-SkyMed 1 \\
$26 / 01 / 2018$ & COSMO-SkyMed 2 \\
$30 / 01 / 2018$ & COSMO-SkyMed 4 \\
\hline
\end{tabular}

After image coregistration of the stack of Level 1A complex products to achieve subpixel precision, five interferometric SAR pairs (Table 2) were formed with the objectives to:

- temporally capture the two events via cross-event pairs, i.e., pre-event versus post-event scenes: one pair for the December 2014 event (i.e., 10/07/2014-12/04/2015), and three for the January 2018 event (i.e., 13/12/2017-30/01/2018, 10/01/2018-30/01/2018, and 26/01/2018-30/01/2018);

- $\quad$ analyse the areas where the two events occurred, but during time periods unaffected by the events themselves, in particular: before the January 2018 event (i.e., 18/01/2018-26/01/2018), and after the December 2014 event (i.e., 13/12/2017-30/01/2018).

Differential interferograms were generated from the selected image pairs by subtracting topographic phase information based on NASA's shuttle radar topography mission (SRTM) global digital elevation model (DEM) at 1 arc-sec $(\sim 30 \mathrm{~m})$ spatial resolution. No multilooking for the creation of the interferograms was employed, in order to keep the original scene resolution in range and azimuth. However, a Gaussian weighting filter with an adaptive window size of 3 to 5 pixels, as well as 
range spectral shift filtering and azimuth common-band filtering, were exploited during the estimation of interferometric coherence $(\gamma)$. The latter is a dimensionless number ranging between 0 and 1 that indicates the quality of interferometric fringes and can be estimated as the absolute value of the cross-correlation coefficient between two complex SAR images. Interferometric coherence therefore quantifies the degree of correlation between phase and amplitude information of the two images forming the pair, with $\gamma=0$ indicating no coherence and $\gamma=1$ a perfect correlation. The use of an adaptive window size for the estimation of coherence allowed a trade-off between the spatial resolution of the estimation and the estimation bias. This is achieved by using a smaller window size in high-coherence areas to keep the highest possible resolution and a larger window size in low-coherence areas (e.g., $\gamma$ of $0.1-0.3$ ) to minimise the bias.

Table 2. Dates and perpendicular $\left(B_{p}\right)$ and temporal $\left(B_{t}\right)$ baselines of the COSMO-SkyMed InSAR pairs used for the analysis of the December 2014 and January 2018 events that occurred at the Nasca Lines.

\begin{tabular}{cccc}
\hline InSAR Pair (DD/MM/YYYY) & $\boldsymbol{B}_{\boldsymbol{t}}$ [days] & $\boldsymbol{B}_{\boldsymbol{p}}[\mathbf{m}]$ & Figures \\
\hline $10 / 07 / 2014-12 / 04 / 2015$ & 275 & 14 & Figure 6b \\
$13 / 12 / 2017-30 / 01 / 2018$ & 48 & 19 & Figures 3e, 4e and 6c \\
$10 / 01 / 2018-30 / 01 / 2018$ & 20 & 165 & Figures 3d and 4d \\
$18 / 01 / 2018-26 / 01 / 2018$ & 8 & 4 & Figures 3b and 4b \\
$26 / 01 / 2018-30 / 01 / 2018$ & 4 & 472 & Figures 3c and 4c \\
\hline
\end{tabular}

A wealth of other COSMO-SkyMed StripMap HIMAGE scenes acquired over the Nasca Lines exists in the data catalogue since 2011, which are potentially available to create many other interferometric pair combinations. Nevertheless, the abovementioned scenes and respective pairs were the only ones allowing both a suitable temporal sampling of the two selected events, and the optimisation of temporal $\left(B_{t}\right)$ and normal baseline $\left(B_{p}\right)$ combinations to minimize temporal and geometric decorrelation (Table 2). This enhanced the potential to identify decorrelation instances due to the events and reduce coherence loss due to baseline differences. The advantage in terms of data availability offered by the rich catalogue of COSMO-SkyMed scenes was therefore exploited to increase the opportunities for SAR image selection and consequent InSAR pair combination, and to undertake a more comprehensive change detection analysis of the two selected events of site disturbance (see discussion in Sections 3.1 and 3.2).

The seven COSMO-SkyMed scenes and their derived products were ultimately geocoded to map geometry using the WGS84 ellipsoid, and ingested into a GIS environment to carry out the interpretation of the events.

Precise geolocation of the two events in the WGS84 datum was inferred based on one DigitalGlobe VHR satellite image acquired on 29/05/2013 and available in Google Earth.

Photographic and video evidence published on the web in relation to the two events, as well as literature, web news, reports, and press releases, were used to extract supporting information about the geolocation and spatial extent of the two events.

In order to verify if any surface reflectance changes occurred, HR imagery acquired by the Sentinel-2B satellite of the Copernicus multispectral Sentinel-2 constellation before (18/01/2018) and after (28/01/2018) the January 2018 event was also analysed. In particular, among the 13 visible to near and short-wave infrared spectral bands acquired by the MultiSpectral Instrument (MSI) onboard Sentinel-2B, the 10-m spatial resolution B2 $(490 \mathrm{~nm})$, B3 $(560 \mathrm{~nm})$, and B4 $(665 \mathrm{~nm})$ bands in the visible region of the spectrum were used. No Sentinel-2 image could be retrieved for the December 2014 event, because neither of the two Sentinel-2 satellites had been launched yet at that time.

\section{Results and Discussion}

Figures 3-6 show the results of the InSAR coherence and change detection analysis for the two events that occurred in January 2018 and December 2014, which are analysed and discussed in detail 
in Sections 3.1 and 3.2, respectively. A nonchronological order for the presentation of the two events of site disturbance was intentionally adopted to: (i) first demonstrate what can be achieved for a recent event, only a few days or weeks after its occurrence; and (ii) then export the same approach to a much older event. This is achieved by going back through the time series, to showcase that the same stack of SAR data can also be exploited at any time to reconstruct historical events, as well as to verify present site condition and confirm the absence or presence of further landscape disturbance.

InSAR coherence maps in Figure $3 b-e$, Figures $4 b-e$ and $6 b, c$ use a colour scale, whereby areas with high coherence are represented in yellow, whilst low-coherence areas are represented in dark violet. This colour scale enhances very well the identification of sectors where coherence drops due to temporal and/or spatial decorrelation. The interpretation of the causes for coherence loss is then carried out by accounting for the characteristics of the InSAR pairs (e.g., $B_{t}$ and $B_{p}$ ), other ancillary information about the two events, and evidence from the analysis of VHR and HR satellite data.

The Sentinel-2B multispectral imagery in Figure $5 b, c$ is represented in a true colour red-green-blue (RGB) full-resolution combination of its 10-m resolution bands B4 (red), B3 (green), and B2 (blue), to allow comparison with VHR data from Google Earth and recognition of surface reflectance changes in the visible region of the spectrum.

\subsection{The 2018 "Plowing" Event}

In its press release of 29 January 2018 [9], the Ministry of Culture in Peru reported that despite the presence of warning signage indicating the heritage site and prohibiting access to the protected area, in the late afternoon of 27 January 2018, a truck diverted off the paving of the Pan-American Highway at kilometre 424 and entered the protected area. A series of aerial photographs was collected by the Ministry on 28 January 2018 at 8.30 am by using a camera onboard a drone [9], and revealed that the incident visibly disturbed the area $[22,23]$. In particular, the truck crossed over three linear geoglyphs, and left deep tire marks across an area of 50 by $100 \mathrm{~m}$ [9].

The photographs available online suggest that the truck was travelling towards the southeast (i.e., the direction of Nasca), and drove off the road around $100 \mathrm{~m}$ before a guardhouse installation point along the Pan-American Highway (see also Figure 2a for reference). The tire marks run for $100 \mathrm{~m}$ from the entrance point off the highway and towards the guardhouse and then turn right towards the west. Videos published on the web (e.g., [24]) show that the truck was parked 20-30 m away from the guardhouse before sunset on 27 January 2018. From this position, the truck likely was then driven back onto the highway towards the northwest (i.e., the direction of Palpa) after the incident.

Based on published web evidence and the analysis of the VHR optical image in Google Earth, the location of the event can be placed at approximately $14^{\circ} 41^{\prime} 22^{\prime \prime} \mathrm{S}, 75^{\circ} 07^{\prime} 05^{\prime \prime} \mathrm{W}$, just off the southwestern side of the Pan-American Highway (see black star in Figure 1). Figure 4a schematically represents: (i) a sketch of the tire marks left by the truck, as inferred based on photographic evidence [22,23]; (ii) the position of the truck on 27 January 2018, as inferred based on the video [24]; and (iii) the location of the guardhouse, as determined via the VHR Google Earth image (see also Figure 2a). It is understood that this is not meant to be a forensic reconstruction of the event, but rather an attempt to spatially map objects and marks to better interpret the patterns found in the InSAR coherence maps.

The surface disturbance that was caused by the "plowing" and was captured in the photographs consists in the alteration of the fragile surface of the Pampa de Jumana via removal of the reddish pebble and the uncovering of the much lighter grey-yellow clay underneath.

Figure 3 provides a zoom onto the section of the Pan-American Highway that runs across the Pampa in its transect richest in geoglyphs and lines, including the area where the 2018 event occurred and also where the 13-m tall observation tower (Torre Mirador de Las Lines de Nasca) is located. Up from the latter, tourists can get a panoramic outlook of the Pampa and a close-up view of some of the geoglyphs, such as the "Hands" (Las Manos) and "Tree" (Arbol), as indicated in Figure $2 b$. 


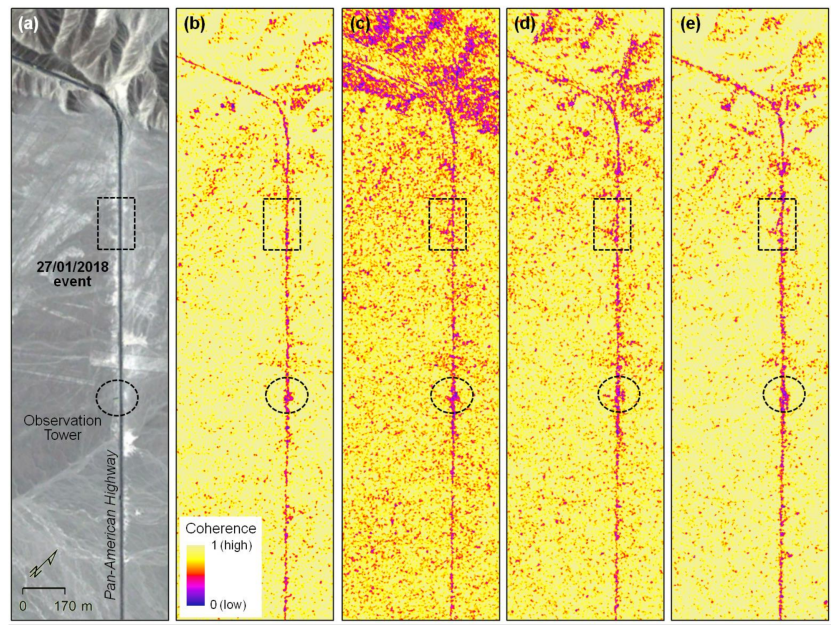

Figure 3. Analysis of the 27/01/2018 event: (a) Google Earth overview of the Pan-American Highway (VHR image (c) 2018 DigitalGlobe), with the locations of the event and Observation Tower marked by the dashed rectangle and oval, respectively; and (b-e) InSAR coherence $\gamma$ for a series of COSMO-SkyMed StripMap pairs: (b) 18/01/2018-26/01/2018 (pre-event); (c) 26/01/2018-30/01/2018 (cross-event); (d) 10/01/2018-30/01/2018 (cross-event); and (e) 13/12/2017-30/01/2018 (cross-event).
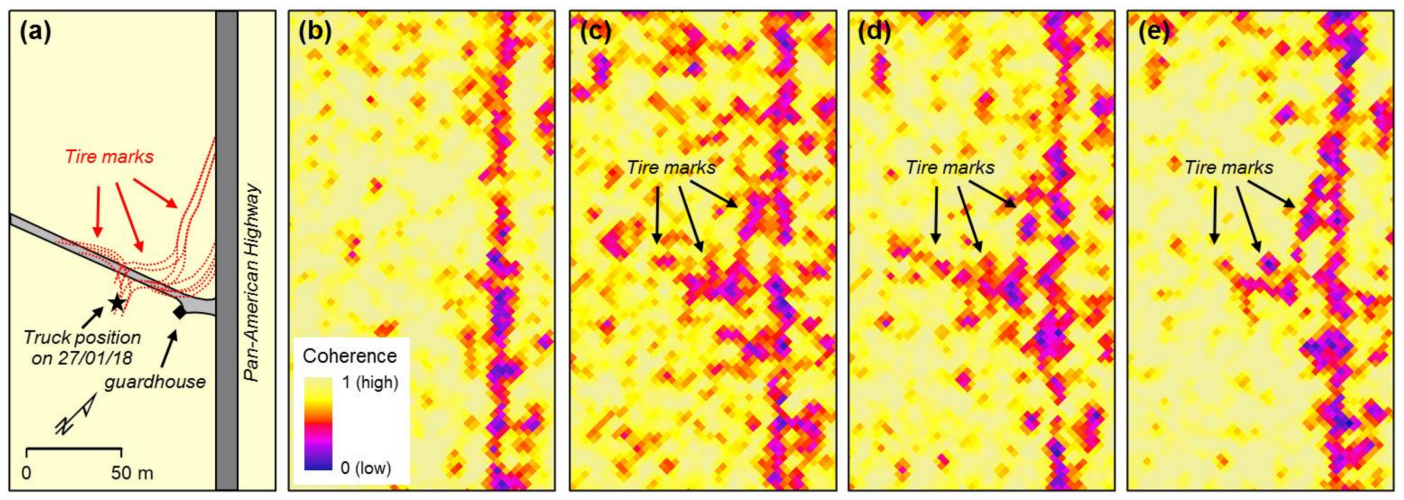

Figure 4. (a) Sketch of the tire marks left by the truck on 27/01/2018 (as inferred based on photographic evidence in [22,23]), with indication of the position of the truck during the incident (black star; as inferred based on the video in [24]); and (b-e) InSAR coherence $\gamma$ for the COSMO-SkyMed StripMap pairs: (b) 18/01/2018-26/01/2018 (pre-event); (c) 26/01/2018-30/01/2018 (cross-event); (d) 10/01/2018-30/01/2018 (cross-event); and (e) 13/12/2017-30/01/2018 (cross-event).

Overall, the analysis of InSAR coherence maps for one pre-event (18/01/2018-26/01/2018; Figure 3b) and three cross-event (26/01/2018-30/01/2018, 10/01/2018-30/01/2018, and 13/12/2017-30/01/2018; Figure $3 c-e)$ pairs reveals that generally most of the area shows high to very high coherence values $(\gamma$ of 0.7 to over 0.9 ) across the Pampa. This indicates good correlation between the COSMO-SkyMed images composing each InSAR pair and the absence of significant elements of decorrelation.

Apparent coherence loss and drop to values lower than 0.4 are observed for the following areas, due to a combination of imaging-related causes and human activity:

- Pampa de Jumana: coherence across the plain decreases with increasing normal baselines due to geometric decorrelation. Pairs 26/01/2018-30/01/2018 ( $B_{p}$ of $472 \mathrm{~m}$ ) and 10/01/2018-30/01/2018 $\left(B_{p}\right.$ of $\left.165 \mathrm{~m}\right)$ in Figure $3 \mathrm{c}, \mathrm{d}$ highlight a much more pronounced effect of geometric decorrelation than pairs 18/01/2018-26/01/2018 ( $B_{p}$ of $4 \mathrm{~m}$ ) and 13/12/2017-30/01/2018 ( $B_{p}$ of $\left.19 \mathrm{~m}\right)$ in Figure $3 \mathrm{~b}$,e. This effect is also clearly enhanced in the northwesternmost part of the area due to the presence of topography. 
- Pan-American Highway: here decorrelation occurs as an effect of cars and trucks driving along the road and thus generating temporal decorrelation in all InSAR pair combinations. The effects of vehicular decorrelation are more evident with increasing temporal baselines. For instance, pair 13/12/2017-30/01/2018 in Figure 3e with a $B_{t}$ of 48 days shows a much more marked decorrelation feature along the highway than pair 18/01/2018-26/01/2018 in Figure $3 b$ with a $B_{t}$ of only 8 days.

- Observation Tower: at this location, coherence loss extends some meters off the Pan-American Highway due to the transit of tourists visiting the tower. Decorrelation is observed both to the southwest of the highway at the tower location (e.g., Figure 3c), and to the opposite side, where its small parking lot occupies an area of about 10 by $20 \mathrm{~m}$ adjacent to the highway (e.g., Figure 3d,e; see also Figure 2b).

- January 2018 incident: decorrelation in the three cross-event InSAR pairs is observed in the area identified as that affected by the 2018 event (Figure 3c-e). A detailed analysis of coherence for this area is provided in Figure $4 \mathrm{~b}-\mathrm{e}$, where the same InSAR pairs are shown by zooming in at the local scale. In the pre-event 18/01/2018-26/01/2018 pair (Figure 4b), there are no obvious coherence loss marks other than those along the highway due to vehicle transit and a few spots of possible human/vehicle transit along the verge of the highway. On the other hand, some very noticeable marks appear in the three cross-event pairs in Figure $4 \mathrm{c}-\mathrm{e}$. The decorrelation marks seem to follow the exact path that was followed by the truck during the incident, with the main linear feature originating from the highway and moving off it towards the guardhouse. The feature is best depicted in the InSAR pair 13/12/2017-30/01/2018 (Figure 4e) which is the cross-event pair characterised by the smallest $B_{p}$ but longest $B_{t}$ among all the cross-event pairs. Comparison of the pre- and post-event Sentinel-2 scenes for this area (Figure 5) confirms the occurrence of a slight surface reflectance change, even at the 10-m image resolution. The increase in reflectance is due to plowing of the surface and uncovering of the light grey-yellow clay underneath the darker pebble constituting the surface of the Pampa. It is to be noted, however, that the spatial resolution of Sentinel-2 data does not allow precise spatial delineation of the site disturbance at the scale of this event. In this case, a post-event optical scene with higher spatial resolution would have been necessary to identify accurately the surface reflectance change marks. No post-event VHR imagery is, however, currently available via Google Earth, where the most recent scene for this location dates back to 20/10/2014.
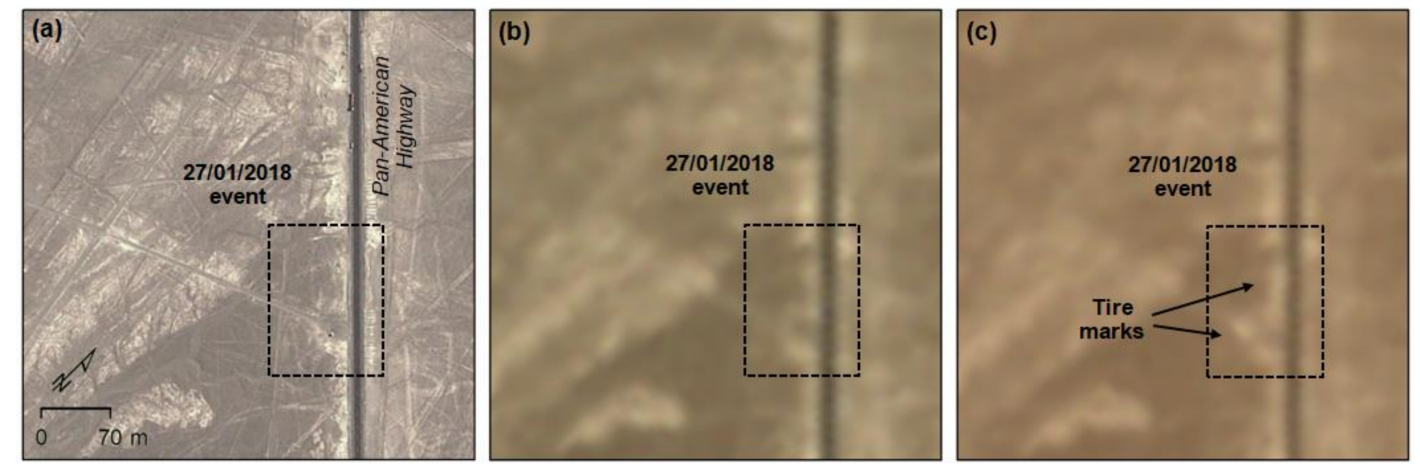

Figure 5. (a) Google Earth overview of the area where the 27/01/2018 incident occurred (VHR image (C) 2018 DigitalGlobe), and (b,c) comparison of Sentinel-2B: (b) pre-event (18/01/2018); and (c) post-event (28/01/2018) true colour images (Copernicus Sentinel-2 data (C 2018 European Space Agency, ESA). The deep tire marks left by the truck during the incident are indicated in the post-event scene, which shows a local increase in surface reflectance. 


\subsection{The 2014 Surface Disturbance Event}

In its press release of 9 December 2014 [10], the Ministry of Culture in Peru reported about an event that occurred very early in the morning on 8 December 2014. Environmental activists accessed the area near one of the most famous geoglyphs of Nasca, known as the "Hummingbird" (El Colibrí), and unfurled tall, yellow cloth letters under the bird's beak to compose a message [25].

Photographic evidence collected by the Ministry in the following days [26,27], as well as the photographs and videos published in the web media [28], clarified the type and extent of the damage observed. In particular, the in situ inspections highlighted that "the route followed to access the geoglyph was irreparably marked, in addition to the disturbance of the surrounding terrain of the figure of the Hummingbird due to the movement and circulation of people", the latter affecting a nearly rectangular area with an extent of around $1600 \mathrm{~m}^{2}$ [29].

For the purposes of this retrospective analysis, the above background information suggested that an event such as this could cause changes at the surface that could have been captured in the archive COSMO-SkyMed satellite SAR images and could be extracted to create a digital record. In this regard, corroboration can be found in the scientific results that were recently published in $[17,30]$. These authors used a pair of pre- and post-event airborne L-band SAR VHR scenes (March 2013 vs March 2015) that were acquired from NASA's uninhabited aerial vehicle SAR (UAVSAR) platform, and they found highly decorrelated zones indicating apparent surface disturbance due to the December 2014 event.

Figure 6a shows a zoom down onto the plateau where the Hummingbird is carved (see also Figure 2c), with a rough delineation of the area affected by the 2014 event as reported in [31], which is centred at approximately $14^{\circ} 41^{\prime} 30^{\prime \prime} \mathrm{S}, 75^{\circ} 08^{\prime} 56^{\prime \prime} \mathrm{W}$ and has an overall extent of around $2000 \mathrm{~m}^{2}$.
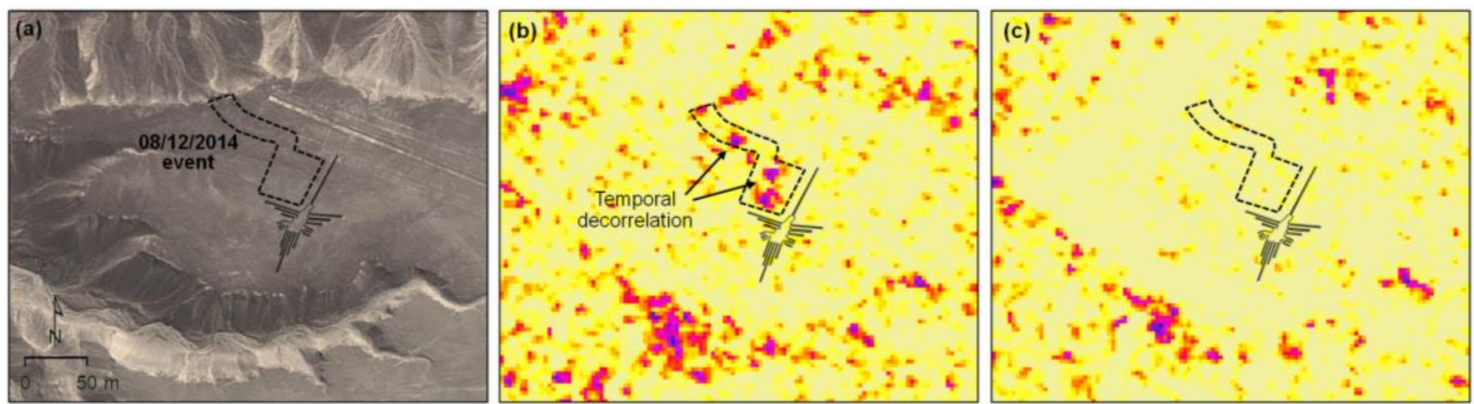

Figure 6. (a) Google Earth overview of the plateau where the Hummingbird geoglyph is carved (VHR image (C) 2018 DigitalGlobe), with a sketch of the geoglyph and indication of the area affected by the 08/12/2014 incident as delineated in [31]; and (b,c) InSAR coherence $\gamma$ for two COSMO-SkyMed StripMap pairs: (b) 10/07/2014-12/04/2015 (cross-event) and (c) 13/12/2017-30/01/2018 (post-event).

Figure $6 \mathrm{~b}, \mathrm{c}$ compares two InSAR coherence maps generated using one cross-event (10/07/2014-12/04/2015) and a very recent post-event (13/12/2017-30/01/2018) COSMO-SkyMed pair.

In the post-event pair, the plateau shows generally very high coherence with $\gamma$ values of $0.8-0.9$ (Figure 6c), thus indicating the absence of recent surface disturbance in the area of the geoglyph. Only a few spots of coherence loss in the valleys around the plateau can be observed, and they are mainly due to the presence of topography and geometric decorrelation.

Analysis of the pre- versus post-event scenes instead allows the identification of a noticeable decorrelation feature to the west and northwest of the Hummingbird geoglyph (Figure 6b). This seems to match very well with the area where the disturbance occurred, including both where the message by the activists was temporally installed on 8 December 2014 and the path that was delineated in [29,31]. Despite the relatively small $B_{p}$ of $14 \mathrm{~m}$ of the cross-event InSAR pair, the effect of decorrelation due 
to the temporal baseline of 275 days is much more apparent also in the valleys around the plateau, whereas coherence across the plateau is generally high (except in the area of the incident).

The shape and extent of the decorrelated area indicating surface disturbance in Figure $6 \mathrm{~b}$ is similar to that found via the UAVSAR VHR campaign presented in $[17,30]$.

\section{Conclusions}

The objective of this study was to demonstrate the feasibility and performance of change detection based on InSAR coherence to create digital records of condition assessment of heritage assets in circumstances of known human-induced landscape disturbance. This objective was achieved via an analysis of the SAR signal recorded in a regular, frequent, and consistent COSMO-SkyMed acquisition schedule over two selected areas of the Nasca Lines WHS in Peru that were affected by site disturbance events in 2014 and 2018.

The method was intentionally tested on two different temporal scales to prove the advantages offered by a high-resolution SAR archive for both retrospective analysis of past incidents (e.g., December 2014) and substantiation of events soon after they have occurred (e.g., January 2018).

Because the COSMO-SkyMed constellation is tasked to acquire SAR images over the Nasca Lines with a predefined observation scenario at a regular temporal sampling, it is possible to create multiple InSAR coherence pairs between pre- and post-event images that allow the optimisation of $B_{t}$ and $B_{p}$ combinations in order to minimize temporal and geometric decorrelation. In the case of the site disturbance that happened in January 2018, the various cross-event InSAR pairs that were generated and analysed led to a positive redundancy of information on the temporal decorrelation caused by the disturbance. In the multitemporal domain, the analysis allowed the enhancement of the spatial patterns of low-coherence areas $(\gamma<0.4)$ where the tire marks were left by the truck against a clean pre-event baseline InSAR record.

This result has been achieved in this study under different SAR imaging conditions than the common single-pair approach that is used in change detection analysis. Usually, change detection of a known event is carried out by acquiring an ad hoc image soon after (or, if possible, even during) the event of interest, and by relying on the temporal granularity that is allowed by the availability of an archive image already acquired before the event. Typically, this is the only option, unless the study area is already covered by a consistent and abundant SAR archive or is a known hotspot that is regularly monitored. In Nasca, on the other hand, the study benefitted from a different change detection paradigm. A COSMO-SkyMed high-resolution SAR time series is being acquired since 2011, and consequently, the probability that unexpected events can be captured in a timely manner in the images is higher, regardless of when the data analysis and creation of the associated digital record are undertaken.

The experiments described in this paper prove that growing SAR image archives, such as that currently being built by the COSMO-SkyMed constellation in Nasca, can be great assets towards a sustainable approach of heritage conservation. In particular, they can be extremely valuable in situations where the site managers themselves acknowledge the practical difficulties of monitoring widespread heritage assets and huge cultural landscapes (see [22] with specific regard to the Nasca Lines WHS). In summary, growing and consistent SAR archives provide a wider spectrum of imaging solutions to capture events of site disturbance, reduce the constraints due to insufficient or missing data, and enable the operators to create digital records from remote and at any time. These are all properties of sustainability, and contribute towards sustainable archaeology and the conservation of cultural heritage sites. On the other side, the prerequisites for effective exploitation of these archives are knowledge of the events, maintenance of the archives, and training of the operators to use and interpret these space-borne data and their derived products.

Acknowledgments: Project carried out using COSMO-SkyMed ${ }^{\circledR}$ Products, $($ C of the Italian Space Agency (ASI), delivered under a licence to use by ASI. VHR imagery (๑ 2018 DigitalGlobe) was analysed in Google Earth Pro. NASA's 1 arc-sec SRTM global DEM was made available by USGS via the LP DAAC Global Data 
Explorer. Copernicus Sentinel-2B scenes were sourced from the European Space Agency (ESA) Copernicus Open Access Hub.

Author Contributions: F.C. and D.T. designed and carried out the experiments, analysed the data, and wrote the paper.

Conflicts of Interest: The authors declare no conflicts of interest.

\section{References}

1. Reinhard, J. The Nazca Lines: A New Perspective on Their Origin and Meaning, 6th ed.; Los Pinos: Lima, Peru, 1996.

2. Lambers, K. Chapter 4.1: Los geoglifos: Imágenes y escenarios en el desierto de Nazca y Palpa [In Spanish] /The geoglyphs: images and settings in the desert of Nazca and Palpa. In Nasca; Pardo, C., Fux, P., Eds.; Asociación Museo de Arte de Lima: Lima, Peru, 2017; pp. 112-123, 362-367.

3. UNESCO. Lines and Geoglyphs of Nasca and Palpa. Available online: http://whc.unesco.org/en/list/700 (accessed on 11 March 2018).

4. UNESCO. State of Conservation: Lines and Geoglyphs of Nasca and Palpa (Peru). Report 2013. Available online: http:/ / whc.unesco.org/en/soc/1994 (accessed on 11 March 2018).

5. TeleSUR. Peru Seeks to Protect Ancient Nazca Lines from El Niño (20 Nov 2015). Available online: https: / /www.telesurtv.net/english/news/Peru-Seeks-to-Protect-Ancient-Nazca-Lines-from-ElNino-20151120-0004.html (accessed on 11 March 2018).

6. World Monuments Fund (WMF). Lines and Geoglyphs of Nasca. Available online: https://www.wmf.org/ project/lines-and-geoglyphs-nasca (accessed on 11 March 2018).

7. Perù21. Confirman daño en las líneas de Nasca (29 Apr 2013) [In Spanish]. Available online: https: / / peru21.pe/opinion/confirman-dano-lineas-nasca-102740 (accessed on 11 March 2018).

8. El Comercio Líneas de Nasca: este es el daño provocado a geoglifos (26 Sept 2015) [In Spanish]. Available online: https: / / elcomercio.pe/peru/ica/lineas-nasca-dano-provocado-geoglifos-fotos-220884? foto $=4$ (accessed on 11 March 2018).

9. Ministerio de Cultura. COMUNICADO: Ministerio de Cultura denuncia penalmente a chofer de camión que ingresó a la Pampa de Nasca (29 Jan 2018) [In Spanish]. Available online: http:/ / www.cultura.gob.pe/es / comunicacion/noticia/comunicado-ministerio-de-cultura-denuncia-penalmente-chofer-de-camion-que (accessed on 29 January 2018).

10. Ministerio de Cultura. COMUNICADO: Ministerio de Cultura se pronuncia sobre atentado en las Líneas de Nasca (9 Dec 2014) [In Spanish]. Available online: http:/ / www.cultura.gob.pe/es/comunicacion/noticia/ ministerio-de-cultura-se-pronuncia-sobre-atentado-en-las-lineas-de-nasca (accessed on 11 March 2018).

11. Cigna, F.; Tapete, D.; Lasaponara, R.; Masini, N. Amplitude change detection with ENVISAT ASAR to image the cultural landscape of the Nasca region, Peru. Archaeol. Prospect. 2013, 20, 117-131. [CrossRef]

12. Tapete, D.; Cigna, F.; Masini, N.; Lasaponara, R. Prospection and monitoring of the archaeological heritage of Nasca, Peru, with ENVISAT ASAR. Archaeol. Prospect. 2013, 20, 133-147. [CrossRef]

13. Ruescas, A.; Delgado, J.; Costantini, F.; Sarti, F. Change Detection by Interferometric Coherence in Nasca Lines, Peru (1997-2004). In Proceedings of the Fringe 2009 Workshop, Frascati, Italy, 30 November-4 December 2009; p. 7.

14. Lefort, A.; Grippa, M.; Walker, N.; Stewart, L.J.; Woodhouse, I.H. Change detection across the Nasca pampa using spaceborne SAR interferometry. Int. J. Remote Sens. 2004, 25, 1799-1803. [CrossRef]

15. Tapete, D.; Cigna, F. Trends and perspectives of space-borne SAR remote sensing for archaeological landscape and cultural heritage applications. J. Archaeol. Sci. Rep. 2017, 14, 716-726. [CrossRef]

16. Baade, J.; Schmullius, C. High-resolution mapping of fluvial landform change in arid environments using TerraSAR-X images. In Proceedings of the 2010 IEEE International Geoscience and Remote Sensing Symposium, Honolulu, HI, USA, 25-30 July 2010; pp. 2159-2162.

17. Comer, D.C.; Chapman, B.D.; Comer, J.A. Detecting Landscape Disturbance at the Nasca Lines Using SAR Data Collected from Airborne and Satellite Platforms. Geosciences 2017, 7, 106. [CrossRef]

18. Chavez, N. CNN. Truck driver plows into Peru's 2,000-year-old archeological enigma (1 Feb 2018). Available online: https://edition.cnn.com/2018/02/01/americas/nazca-lines-peru-truck-driver/index. html (accessed on 11 March 2018). 
19. Covello, F.; Battazza, F.; Coletta, A.; Lopinto, E.; Fiorentino, C.; Pietranera, L.; Valentini, G.; Zoffoli, S. COSMO-SkyMed an existing opportunity for observing the Earth. J. Geodyn. 2010, 49, 171-180. [CrossRef]

20. Italian Space Agency (ASI). COSMO-SkyMed System Description \& User Guide (4 May 2007). DOC n. ASI-CSM-ENG-093-A, 49 pp. Available online: http:/ /www.cosmo-skymed.it/docs/ASI-CSM-ENG-RS093-A-CSKSysDescriptionAndUserGuide.pdf (accessed on 11 March 2018).

21. Italian Space Agency (ASI). COSMO-SkyMed Mission and Products Description (31 May 2016). DOC n. ASI-CSM-PMG-NT-001, 151 pp. Available online: http:/ / www.e-geos.it/images/documents/COSMOSkyMedMissionandProductsDescription.pdf (accessed on 11 March 2018).

22. Agencia Andina. Drone Pictures Show Damage to Peru's Ancient Nazca Lines (1 Feb 2018). Available online: http:/ / andina.pe/ingles/noticia.aspx?id=697882 (accessed on 1 February 2018).

23. Little, B. Truck Drives Over 2000-Year-Old Desert Hieroglyphs (2 Feb 2018). Available online: http:/ / www. history.com/news/nazca-lines-damaged-by-truck-peru (accessed on 2 February 2018).

24. Publinews. VIDEO. Un camión daña las milenarias líneas de Nazca, en Perú (30 Jan 2018) [In Spanish]. Available online: https:/ / www.publinews.gt/gt/noticias/2018/01/30/video-camion-dana-las-milenariaslineas-nazca-peru.html (accessed on 11 March 2018).

25. Kozak, R. The Wall Street Journal. Peru Says Greenpeace Permanently Damaged Nazca Lines (15 Dec 2014). Available online: https://www.wsj.com/articles/peru-says-greenpeace-permanently-damaged-nazcalines-1418681478 (accessed on 11 March 2018).

26. Ministerio de Cultura. Ministerio de Cultura inspecciona daños ocasionados en las Líneas de Nasca (13 Dec 2014) [In Spanish]. Available online: http://www.cultura.gob.pe/es/comunicacion/noticia/ ministerio-de-cultura-inspecciona-danos-ocasionados-en-las-lineas-de-nasca (accessed on 11 March 2018).

27. Ministerio de Cultura. Ministerio de Cultura confirma daños en las Líneas de Nasca (15 Dec 2014) [In Spanish]. Available online: http://www.cultura.gob.pe/es/comunicacion/noticia/ministerio-decultura-confirma-danos-en-las-lineas-de-nasca (accessed on 11 March 2018).

28. Ruble, K. Vice News. Drone Footage Shows Extent of Damage From Greenpeace Stunt at Nazca Lines (17 Dec 2014). Available online: https:/ / news.vice.com/article/drone-footage-shows-extent-of-damagefrom-greenpeace-stunt-at-nazca-lines (accessed on 11 March 2018).

29. Ministerio de Cultura. Ministerio de Cultura envía carta a Unesco tras atentado en las Líneas de Nasca (11 Dec 2014) [In Spanish]. Available online: http://www.cultura.gob.pe/es/comunicacion/noticia/ ministerio-de-cultura-envia-carta-unesco-tras-atentado-en-las-lineas-de-nasca (accessed on 11 March 2018).

30. Chapman, B.D.; Comer, D.C.; Isla, J.A.; Silverman, H. The Measurement by Airborne Synthetic Aperture Radar (SAR) of Disturbance Within the Nasca World Heritage Site. Conserv. Manag. Archaeol. Sites 2015, 17, 270-286. [CrossRef]

31. Gonzalez, I.F. Science Salsa. Publicity Stunt Damages Word Heritage Site, Enrages Peruvians (9 Dec 2014). Available online: https:/ / sciencesalsa.com/tag/greenpeace/ (accessed on 11 March 2018). 